This PDF is a selection from an out-of-print volume from the National Bureau of Economic Research

Volume Title: Economics of the Family: Marriage, Children, and Human Capital

Volume Author/Editor: Theodore W. Schultz, ed.

Volume Publisher: University of Chicago Press

Volume ISBN: 0-226-74085-4

Volume URL: http://www.nber.org/books/schu74-1

Publication Date: 1974

Chapter Title: Child Quality and the Demand for Children

Chapter Author: Dennis N. De Tray

Chapter URL: http://www.nber.org/chapters/c2964

Chapter pages in book: (p. 91 - 119) 


\section{Child Quality and the Demand for Children}

\section{Dennis N. De Tray}

RAND Corporation

\section{Introduction}

The past decade has brought a substantial increase in economic analyses of phenomena outside the traditional realm of economics. An already sizable portion of such effort has been directed toward the determinants of desired fertility and family size. ${ }^{1}$ In this paper, I will first consider the degree to which pure economic theory can, or cannot, predict changes in completed fertility. The second, and the major emphasis of the study, is the way in which households produce the household commodity "child services." I argue that households can increase their production of child services either by increasing numbers of children (quantity) or by increasing the resource investment (quality) in existing children. Further, quantity and quality are postulated to be substitutes in the household's production function for child services. After presenting an economic model of desired family size, emphasizing the substitutability of numbers of children and child quality, I will discuss several of the model's important parameters and then offer an empirical formulation based on data from U.S. counties.

This paper is drawn from a more comprehensive study (De Tray 1972a) published by the RAND Corporation. I have benefited greatly from many people's comments and criticisms on earlier drafts, and would especially like to thank Gary Becker, Yoram Ben-Porath, Glen Cain, Marc Nerlove, T. Paul Schultz, T. W. Schultz, and Finis Welch for their many helpful suggestions, not all of which have been incorporated in this paper. $I$, of course, am solely responsible for any remaining errors. The work for this paper was financed in part by grants to the University of Chicago from the National Institute of Mental Health and the Rockefeller Foundation, and by a grant to the RAND Corporation from the Rockefeller Foundation. Views expressed in this paper are mine and not those of any organization with which $I$ am affiliated.

1 See, for example, Becker (1960), Schultz (1969), Willis (1969), Ben-Porath (1970a), Nerlove and Schultz (1970), and Michael (1970).

2 Familiarity with the terminology of the "household production function" model (Becker 1965; Lancaster 1966) is assumed throughout this paper. For a more detailed description of this model, see De Tray (1972a). 


\section{Toward an Economic Model of Desired Family Size}

Children are viewed in this model as home-produced durable assets from whom parents consume a flow of services. This flow varies with both biological units of children (numbers) and with the resource intensity (quality) with which children are raised. No distinction is made between consumer-durable and producer-durable aspects of children in the formal model, although the effect of a positive opportunity cost for child-time (children having value as produced durables) is explored (Section III).

The utility function underlying household behavior has arguments "child services" and a composite commodity, $Z$, representing all other household production-consumption activities. The household utility function can be written as

$$
U=U(C, Z),
$$

where $C$ is the stock of child services.

This study is concerned only with households' determination of the desired stocks of children and not with optimal timing patterns. The model is, therefore, of the one-period, static-state variety in which the household is assumed to make all lifetime decisions at one point in time and to have correctly gauged lifetime conditions. Strictly speaking, it is not $C$ but the flow of services from $C$ that enters the household utility function. However, in order to write the utility function as in equation (1), $C$ need only be measured in "efficiency units," so that total services derived are proportional to the stock.

Assume that all inputs into the various production processes are perfectly divisible and all production functions homogeneous of degree one. ${ }^{3}$ The amount of $Z$ produced and consumed by the household depends on the quantities of time and purchased goods the household allocates to that production process, the state of household technology, and the efficiency with which that production process is undertaken. Inputs may be classified into three categories: male (husband's) time $\left(t_{m}\right)$, female (wife's) time $\left(t_{f}\right)$, and market goods and services $(X) .{ }^{4}$ The efficiency effect is assumed to be a function of the environment in which production takes place, which, in turn, depends primarily on husband's and wife's education.

The production of $C$ is not accomplished directly through inputs of time and goods but by way of two home-produced factors, numbers of children

3 The analysis is complicated, but the major results remain unchanged for homogeneous production functions of degrees other than one.

4 To simplify the model, households are assumed to consist of a husband, a wife, and children only; that is, other adult members are not considered. Also, throughout this study, the terms "male time" and "female time" are used interchangeably with "husband's time" and "wife's time" and should not be confused with hired male and female time. 
$(N)$, and child quality $(Q) .{ }^{5}$ The complete household production framework can be summarized by the following four equations: ${ }^{8}$

$$
\begin{aligned}
& C=C(N, Q) ; \\
& N=N\left(t_{m, N}, t_{f, N}, X_{N} ; \beta, \gamma\right) ; \\
& Q=Q\left(t_{m, Q}, t_{f, Q}, X_{Q} ; \beta, \gamma\right) ; \\
& Z=Z\left(t_{m, Z}, t_{f, Z}, X_{Z} ; \beta, \gamma\right),
\end{aligned}
$$

where $t_{i, j}=$ total time of the $i$ th household member in the production of the $j$ th commodity or input ( $i=m$ ale or female, and $j=Z, N$, or $Q$ ); $\beta=$ generalized index of husband's efficiency in nonmarket production; $\gamma=$ generalized index of wife's efficiency in nonmarket production; and $X_{j}=$ market goods and services in the $j$ th production process.

The form of the production framework may, at first, seem arbitrary in that $N$ and $Q$ might well be viewed as household commodities, thus eliminating equation (2). However, the relationship between $N$ and $Z$ would then be conceptually similar to that between $N$ and $Q$. The model is formulated to emphasize that this may not be the case; that is, a special relationship exists between $N$ and $Q$ that does not exist between $N$ and any other household commodity. In fact, the constant-returns-to-scale assumption restricts the pure derived income elasticities of $N$ and $Q$ to equality in this production framework; and thus the model has at least one testable prediction that separates it from alternative forms. More will be said below on this rather unusual feature of the model.

In arriving at desired lifetime levels of $C$ and $Z$, households maximize equation (1) subject not only to the technological constraint implied by equations (2)-(5) but also to total available lifetime resources. With respect to market goods and services, the household can spend no more than the total earnings of all members plus any initial endowment or wealth transfers (inheritance, dowries, and so on). That is,

$$
X_{o} \cdot P_{C}+X_{Z} \cdot P_{Z} \leqslant Y_{m}+Y_{f}+V,
$$

where $X_{j}=$ market goods and services in the $j$ th production process, $P_{j}=$ per unit price of $X_{j}, Y_{i}=$ lifetime market (wage) earnings of the $i$ th household member, and $V=$ non-wage related income.

The household is also constrained in the time available for work and household production. If $T_{m}$ and $T_{f}$ represent total time of husband and wife respectively, then

${ }^{5}$ For this discussion, quality may be thought of as the resource intensity with which children are produced. The same notion is found in both Becker (1960) and Michael (1970).

${ }^{6}$ Note that the form of the equations implies that each production process is independent-joint production is ruled out. Given the previous assumption of perfectly divisible inputs, this is not a further restriction of the model (see Grossman 197.1). However, since the earlier assumption is unrealistic in certain important respects, in Section III are mentioned possible effects of externalities, joint production, and so on, although the model is not formally amended to take these factors into account. 


$$
\left.\begin{array}{l}
T_{m}=L_{m}+t_{m, c}+t_{m, Z} \\
T_{f}=L_{f}+t_{f, c}+t_{f, Z}
\end{array}\right\},
$$

where $t_{i, j}$, as before, is time of the $i$ th household member in the $j$ th production process, and $L_{i}$ indicates time spent in the market place (working).

Since time can be exchanged for goods at the market wage rate, the two constraints (eqq. [6], [7]) can be combined into the following "full wealth" or lifetime resource constraint:

$$
\begin{aligned}
I & =\pi_{Z} \cdot Z+\pi_{\sigma} \cdot C \\
& =T_{m} \cdot W_{m}+T_{f} \cdot W_{f}+V,
\end{aligned}
$$

where $I=$ household full wealth, $\pi_{j}=$ shadow price to the household of the $j$ th commodity, $W_{m}=$ male lifetime wage rate (per unit time), and $W_{f}=$ female lifetime wage rate (per unit time).

The framework set out above is structured to emphasize the possibility that households can substitute quality for numbers of children in their production of child services. It has also been left unrestricted to illustrate that even in the simplified framework of equations (1)-(8), there are serious problems involved in predicting, a priori, changes in numbers of children.

The following equation, derived in detail in the Appendix, illustrates the complexity of determining changes in the demand for $N$ for given changes in exogenous or predetermined variables in the system: ${ }^{7}$

$$
\begin{aligned}
E N & =(V / I) \eta E V \\
& -\alpha_{X_{V}}\left\{\alpha[k \eta+(1-k) \sigma]+(1-\alpha) \sigma^{*}\right\} E P_{N} \\
& +\alpha_{X_{Q}}(1-\alpha)\left[\sigma^{*}-k \eta-(1-k) \sigma\right] E P_{Q} \\
& +\alpha_{X_{Z}}(1-k)(\sigma-\eta) E P_{Z} \\
& +\left[(1-\alpha) \sigma^{*}\left(\alpha_{t_{m, Q}}-\alpha_{t_{m, N}}\right)+(1-k) \sigma\left(\alpha_{t_{m, Z}}-\alpha_{t_{m, C}}\right)\right. \\
& \left.+\left(Y_{m} / I\right) \eta\right] E W_{m} \\
& +\left[(1-\alpha) \sigma^{*}\left(\alpha_{t_{f, Q}}-\alpha_{t_{f, N}}\right)+(1-k) \sigma\left(\alpha_{t_{f, Z}}-\alpha_{t_{f, \sigma}}\right)\right. \\
& \left.+\left(Y_{f} / I\right) \eta\right] E W_{f} \\
& +(1-\alpha) \sigma^{*}\left(\mu_{N, \beta}-\mu_{Q, \beta}\right)+(1-k) \sigma\left(\mu_{C, \beta}-\mu_{Z, \beta}\right) \\
& +\{1-\alpha) \sigma^{*}\left(\mu_{N, \gamma}-\mu_{Q, \gamma}\right)+(1-k) \sigma\left(\mu_{C, \gamma}-\mu_{Z, \gamma}\right) \\
& \left.+\eta\left[k \mu_{\sigma, \gamma}+(1-k) \mu_{Z, \gamma}\right]\right\} E \gamma,
\end{aligned}
$$

where $E=d(\log )$ operator (percentage change); $V=$ non-wage-related

7 A multitude of simultaneity problems have been brushed aside in this statement. Probably the most important is the interdependence of the market wage rate and the amount of time spent in the home, an especially severe problem for women. For a recent attempt to deal with this, see Nerlove and Schultz (1970). 
income; $I=$ full wealth; $\eta=$ income elasticity of $C$, child services; $a=$ the share of expenditures on $N$ in total expenditures on $C$, that is, $\left(\pi_{N}\right.$. $N) /\left(\pi_{C} \cdot C\right) ; \sigma^{*}=$ the elasticity of substitution between $N$ and $Q$ in the production of $C ; \alpha_{i, j}=$ the share of expenditures on the $i$ th input in total expenditures on the $j$ th output, where $i=X, t_{m}, t_{f}$ and $j=N, Q, Z, C$; $k=$ the share of total expenditures on $C$ in full wealth, $I ; \sigma=$ substitution elasticity between $C$ and $Z$ in $U(C, Z) ; P_{i}=$ price of market goods and services, $X_{i} ; Y_{i}=$ lifetime market earnings of the $i$ th household member; $W_{i}=$ wage of the $i$ th family member; and $\mu_{i, j}=$ the partial elasticity of the $i$ th output with respect to the educational level of the $j$ th household member, $i=N, Q, C, Z$, and $j=\beta, \gamma$.

Although formidable in appearance, this expression is not difficult to interpret. Each line represents the "weighted" effect on $N$ of a change in one price, wealth, or productivity variable. Note that with the exception of two variables ( $V$ and $P_{N}$ ), the signs of the elasticity coefficients are ambiguous. An increase in $V$ will increase the demand for $N$ if $N$ is a normal good, and an increase in $P_{N}$ will lead to a reduction in the demand for $N$. All other coefficients depend on (1) the relative importance of various inputs in the household production functions (as measured by their share in total production costs), (2) the degree to which male and female efficiency affects various production functions, and (3) relative household expenditures on $C$ and $Z$. Unless one is willing to speculate on the magnitudes of these weights and efficiency effects, no a priori conclusions on fertility behavior can be drawn from the model.

A similar equation can be derived for child quality, with equally discouraging results. However, restricting the analysis to the relative amounts of $N$ and $Q$ improves the situation somewhat. Either from the above model, or more simply from a variant of the definition of the elasticity of substitution, ${ }^{8}$ the following relationship for the percentage change in the ratio of $Q$ to $C$ can be derived:

$$
\begin{gathered}
E(Q / N)=E Q-E N=\sigma^{*}\left[\left(\alpha_{t_{m . N}}-\alpha_{t_{m . Q}}\right) E W_{m}+\left(\alpha_{t_{f, N}}-\alpha_{t_{f, Q}}\right) E W_{f}\right. \\
\left.\quad+\left(\alpha_{X_{N}}\right) E P_{N}-\left(\alpha_{X_{Q}}\right) E P_{Q}-\left(\mu_{N . \beta}-\mu_{Q . \beta}\right) E \beta-\left(\mu_{N, \gamma}-\mu_{Q, \gamma}\right) E \gamma\right]
\end{gathered}
$$

where the variables are defined as in equation (9).

If equation (10) were estimatable, several interesting aspects of the model could be explored. Most important, the model assumes that derived

8 The elasticity of substitution between $N$ and $Q$ can be written as $\sigma^{*}=[E(Q / N)]$ / [ $E\left(C_{N} / C_{Q}\right)$, where $C_{Q}$ and $C_{N}$ are representatively the marginal products of $Q$ and $N$ in production of $C$. But, in equilibrium, $\pi_{N} / \pi_{Q}=C_{N} / C_{Q}$; therefore, $\sigma^{*}=\mid E(Q)$ $N)] /\left[E\left(\pi_{y} / \pi_{Q}\right)\right]=[E Q-E N] /\left[E \pi_{N}-E \pi_{Q}\right]$, or $E Q-E N=\sigma^{*}\left(E \pi_{v^{-}}-E \pi_{Q}\right)$. The rest of the proof consists simply of breaking $E \pi_{N}$ and $E \pi_{Q}$ into their constituent parts (see the Appendix for this last step). 
pure income elasticities for $N$ and $Q$ are equal. This assumption runs counter to findings of studies in the demand for household durables and to previous speculations on the observed negative relationship between numbers of children and household income. The formulation has a clear, refutable hypothesis that changes in household full wealth will leave the ratio of $Q$ to $N$ unaffected. Furthermore, it has the advantage of concentrating its explanatory power upon pure price effects.

There are several other important features of the model. One is the separation of price of time (wage rates) and education effects. The model assumes that education can affect household decisions ir lependent of its well-known effect on wage rates. Thus it is meaningful to speak of the effect of a change in education levels holding market time values constant. Serious empirical problems raised by this treatment are discussed below. ${ }^{9}$

Another feature of the model is that the husband and wife are treated symmetrically. Both are permitted either to work in the market place or to engage in household commodity production. Whether one or both choose to specialize depends especially upon the wage of the husband relative to that of the wife and the value of each spouse's time in home production.

\section{Supporting Evidence and Related Issues}

I want to summarize a detailed but nonrigorous discussion (see De Tray $1972 a$ ) of important parameters of the model just presented. I will first try to establish bounds for parameters associated with adult household members and then bounds for child-related parameters, and to indicate throughout the implications these "estimates" have for the model.

\section{Adult Time and Adult Education}

Much of the ambiguity in signs of the coefficients of education (9) stems from a lack of information on relative weights for various inputs. It has of ten been assumed (see, e.g., Willis 1969) that since men spend less time in the home than women, expenditure shares in household production for male time are less than for female time. This assumption is seldom questioned even though male wages are above female wages in most households. ${ }^{10}$ If $\alpha_{i_{i . Z}}$ represents the expenditure share of the $i$ th individual's time in all household production, then it is not obvious a priori which is larger, $\alpha_{t_{m, z}}$ or $\alpha_{t, z}$.

${ }^{9}$ To be sure, there are some conceptual problems; again (see n. 7) they involve the simultaneous nature of the household decision-making process. For example, a woman's decision on the number of years of schooling she chooses to receive in general will not be independent of the number of children she wants.

${ }^{10}$ Based on the Office of Economic Opportunity's Survey of Economic Opportunity, the husband's wage exceeded that of the wife in 81 percent of the households in which both spouses were working. 
That male time in production of child services (however defined) is less important than female time is even more generally accepted. ${ }^{11}$ This seems indisputable at early ages, say for children under 6 years, but one must be cautious in extending this proposition to lifetime considerations. In the notation of equation (9), $\alpha_{t_{m, C}}$ and $\alpha_{t, C}$ are concerned with lifetime allocation of time by husbands and wives and not merely time allocation during the first few years of a child's life; but, for simplicity, $\alpha_{t, c}$ will be assumed larger than $\alpha_{\ell_{m, C}}$.

This model further complicates the analysis of the role of time by assuming that children are produced with two time-using inputs, quality $(Q)$ and numbers $(N)$. Although the direct evidence is scarce (De Tray $1972 a)$, there are scattered indications of the relative importance of husband's and wife's time in the production both of child services and of $Q$ and $N$.

Differences in allocation of time by men and women over the life cycle appear to substantiate the assumption that child-services production is, indeed, more female time-intensive than male time-intensive. In his work on time allocation by households, Smith $(1972 a)$ finds that with an increase in the number of young children in the household, men work more hours per year, but women substantially reduce the hours they work in the labor market. The effect of older children is less clear and does not rule out a reversal of intensities as children grow up.

Other studies of labor-force behavior (Cohen, Rea, and Lerman 1970: Leibowitz 1974) also shed some light on the underlying production functions for $Q$ and $N$. A most important finding of these studies for this paper concerns the effect of children on time spent working by women with differing educational levels. Increasing a wife's educational level appears to increase the time (per child) she reallocates from market work to child rearing even though highly educated women, on the average, have higher market wage rates than do women with less education.

This behavior is open to several interpretations. One could argue that highly educated women (or households they reside in) desire high-quality children, and that the differential labor-force behavior of women by education class is indicative of the female time-intensity of child quality. This explanation has the prediction that, holding all other factors constant, increasing the wife's wage will reduce child quality more than numbers of children.

An alternative explanation, also consistent with the observed behavior, stresses the role of education as an efficiency (entrepreneurial) factor in household production. In this argument, ${ }^{12}$ more-educated women are more

11 Willis (1969), for example, assumes that the role of male time in production of child services is sufficiently small to be ignored.

12 Again, see De Tray (1972a) for the details of this argument and a discussion of related issues such as birth control knowledge, simultaneity problems, and so on. 
efficient at producing child quality relative to numbers of children. Furthermore, an increase in female education is not factor neutral in its effects on marginal products of inputs into the production of $Q$, but increases the value of female time more than the value of other inputs. If this is true, highly educated women will tend to allocate more time per child to childservices production, and produce more quality-intensive children than women with less education. This explanation of female labor-force behavior can be summarized as follows:

$$
\begin{aligned}
& \alpha_{t_{f, v}}>\alpha_{t_{f, Q}} ; \\
& \mu_{C, \gamma}>\mu_{C, \beta} ; \\
& \mu_{Q, \gamma}>\mu_{N, \gamma} .
\end{aligned}
$$

Note that an increase in female wages does not tend to reduce quality per child. Which of these hypotheses better fits the data will be taken up in Section IV.

\section{Child-related Factors}

\section{Child-Time}

No mention has been made as yet of the effect of child-time, or its value, on the household decision-making process. The formal model does not rule out producer-durable aspects of children, but there has been no systematic treatment of this characteristic. However, this factor has been an important consideration in past models of desired family size and thus requires some discussion.

Variation in the value of child-time has often been called upon as one explanation of urban-rural fertility differences. The gist of the argument is that farm children are a financial asset to their parents but city children are not; therefore, farm families will desire larger numbers of children than households in an urban environment, other things being equal. Note that the emphasis is on the market (work) value of child-time. As the household production model emphasizes, time can usually be productively employed within the household as well. One implication of the traditional argument, therefore, is that the elasticity of substitution between child time and "hired" time is larger than that between child-time and adult home-time. If this were not true, parents who live in urban areas could substitute the child-time for their own time in the home, enabling them to allocate more hours to work. ${ }^{13}$ Thus, in household production models rural child-time

13 The argument does not preclude the farm environment from having any effect on desired fertility; it simply reduces the expected magnitude of the effect. In fact, one would predict that the increase in the range of alternative uses for child-time caused by establishing a family business such as farming would have a positive effect on desired fertility. But, unless the new alternative significantly increased the value of child-time to the household, the expected magnitude of the effect would not be large. 
plays conceptually much the same role as urban child-time in the household decision-making process, reducing the expected difference from this source. ${ }^{14}$

The farm setting may affect more than just expected returns from childtime. It may alter the price of both time and market goods and services inputs into children so as to lower the shadow price of child services relative to other household production-consumption. For example, living on a farm may reduce the cost of female time in household production even if the wife's market-productivity level is unchanged. The reduction stems from increased opportunity for joint production which a family-operated business permits. In essence, a farm wife can work and participate in home production simultaneously, reducing the opportunity cost of female time in household production. ${ }^{15}$ If this is true, then female time-intensive commodities $(C)$ will become more attractive to a farm household.

Price effects may also encourage farm families to substitute numbers of children for child quality within their production of child services. Goods inputs into the production of $N$-for example, basic food and shelterare probably cheap in rural areas relative to purchased inputs into the production of $Q-$ for example, schooling, ${ }^{16}$ books, and travel. Under these circumstances, farm families would find $Q$ a costly means of increasing child services and would choose to hold relatively large proportions of that commodity in the form of numbers of children.

If $\pi_{i}^{r}$ is the marginal cost of the $i$ th commodity or input in rural areas, and $\pi_{i}{ }^{u}$ is similarly defined for urban areas, then this discussion implies the following: ${ }^{17}$

$$
\frac{\pi_{N}^{r}}{\pi_{Q}^{r}}<\frac{\pi_{N^{u}}}{\pi_{Q}{ }^{u}} .
$$

\section{Infant Mortality}

The discussion so far has treated both $N$ and $Q$ as expected values, ignoring such problems as uncertainty and poor forecasting: The effect of infant mortality on desired family size requires elaboration, however ${ }_{n}$ since in the empirical formulation of the model the proxy for desired family size is not net of expected infant losses. To correct for this, the usual procedure is

14 Large differences cannot be ruled out, given the empirical nature of the issue. The purpose of the statement is to emphasize that the matter is one of degree, not of direction.

15 Glen Cain has pointed out that farm children may require less supervision, that is, are less time-intensive, than urban children and consequently are less costly from that standpoint also.

${ }^{16}$ The case for schooling seems clear from Finis Welch's work (1966) on ouality of education. Welch found that rural areas were at a disadvantage compared with more densely populated areas in the production of "education" because rural schools were too small to take advantage of the apparently large economies of scale in education production.

${ }^{17}$ For given levels of $Q$ and $N$. 
to enter a measure of infant or child mortality as an independent variable in regressions on desired numbers of children. Traditionally, the predicted sign for this variable has been positive, based on the argument that high infant mortality causes parents to bear a relatively large number of children to ensure a given number surviving to adulthood. Note that in this theory the implicit assumption that leads to the predicted positive relationship is that, other things being equal, all parents desire the same number of surviving children, regardless of the infant mortality levels they expect. To justify this assumption, either the demand for surviving children must be perfectly inelastic, or the cost of an infant death must be zero. It is unlikely that either of these conditions holds; in fact, economic theory would lead us to argue that one factor on which parents base their "target" family size is expected losses from infant deaths or, more accurately, the costs associated with these losses. Thus, whether an increase in infant mortality raises or lowers observed numbers of children-ever-born will depend in part on the costs associated with infant deaths (both pecuniary and psychic), and on the elasticity of demand for surviving children.

As O'Hara (1972) points out, other forces, specifically the substitution between $Q$ and $N$ in the household's production of child services, may encourage parents to have large numbers of children, holding other things constant, in a regime of high infant mortality. The important distinction, however, is that these forces do not imply the strong "replacement" relationship that the traditional argument does. To summarize, if $\operatorname{Pr}$ represents the probability that an infant will survive to adulthood, then,

$$
\begin{aligned}
& \frac{\partial N}{\partial P r} \geq 0 ; \\
& \frac{\partial Q / N}{\partial P r}>0 .
\end{aligned}
$$

\section{Summary and Predictions of the Model}

Although the model and subsequent discussion result in few unambiguous predictions, ${ }^{18}$ we are left with strong expectations on the signs of certain coefficients in equations (9) and (10).

In equation (9), female variables should "dominate" male variables. The effect of a change in female education or wage rates should be larger in absolute terms and contribute more to the explanatory power of the estimated equation than changes in male education or wages. Furthermore, since the female wage coefficient contains large negative substitution effects, and that for the male does not, the former should be arithmetically smaller

18 In fact, in equation (9), if (as is true) separate measures of the price of market goods and services inputs into $Q$ and $N$ are not available, the only remaining prediction is that an increase in non-wage-related income should increase the demand for $N$. 
than the latter. If both $C$ and $N$ are female time-intensive, the sign for the female wage coefficient should, in fact, be negative.

Along similar lines, the sign of the female education coefficient should reflect the nonneutral efficiency effect of that variable on the production of $N$ and $Q$, and thus should be arithmetically smaller than the male education coefficient. Again the female coefficient is likely to be negative if the differential efficiency effect is a significant factor.

Since the primary purpose of equation (10) is a qualitative estimate of the relative shares of inputs into $N$ and $Q$, predictions are less apropos than for equation (9). Nonetheless, the theory and discussion imply two propositions. First, if the effect of female education is predominantly on the production efficiency of $Q$, then $\mu_{Q, \gamma}-\mu_{N, \gamma}$ should be positive. Second, household full wealth (or non-wage-related income) should have no effect on the relative level of $Q$ to $N$.

If the model is a useful representation of household decisions about desired family size, we would also expect certain consistencies in the behavior of variables between the two equations. One has already been mentionedfemale education should have a negative coefficient in equation (9) and a positive one in equation (10). Another is that the coefficient for female wage rate should be arithmetically smaller in equation (9) than (10), because of the female time-intensity of child services in general. A third is that the index of the price of market goods and services used in the estimations should exhibit consistent behavior in both equations.

The most important implied consistency from the standpoint of testing this particular form of the fertility model, however, is that for the behavior of household full wealth in the two equations. As equation (9) indicates, a non-wage-related increase in full wealth should unambiguously increase the demand for numbers of children. In contrast, that same variable in equation (10) should have neither positive nor negative effects on the dependent variable, since it is assumed to affect $N$ and $Q$ equally.

\section{An Empirical Formulation of the Model}

The results of a preliminary empirical investigation of the derived-demand equations for numbers of children (9) and quality per child (10) follow. The estimates are based on aggregate data drawn from a cross section of U.S. counties.

\section{The Data ${ }^{10}$}

The regression sample consists of 555 counties randomly selected from the approximately 3,300 counties of the continental United States; the primary

\footnotetext{
19 A more detailed description of the data, including a list of the counties in the sample, is given in De Tray (1972a).
} 
data source is the 1960 U.S. Census of Population (U.S., Bureau of the Census $1963 b$ ). Since these data are cross-sectional, they have a number of shortcomings. First, they fail to capture the dynamic nature of the decisionmaking process. Second, for the women who make up the sample, relevant values of the variables are those $10-20$ years prior to $1960 .^{20}$ Third, the theory yields equations whose form requires that the variables be expressed in percentage changes, while the data are measures of levels. ${ }^{21}$

\section{The Variables}

The two dependent variables in the theoretical framework are numbers of children, $N$, and quality per child, $Q / N$. The numbers-of-children variable has a relatively close empirical counterpart, children-ever-born to women of sufficient age to have completed families. ${ }^{22}$ For this analysis women aged 35-44 were chosen as the group with essentially completed fertility. ${ }^{23}$

Constructing an operational measure of child quality is a more difficult task. One approximate measure, in one sense of the term, is the expected full wealth of the child. The best available statistic summarizing a child's future economic prospects is the amount of education that child will receive. With the additional assumption that parents base their expectations on current conditions, quality per child is empirically estimated by the following formula:

$$
\operatorname{EXPED}_{j}=\sum_{i=1}^{n}\left(\frac{\mathrm{ENR}_{i, j}}{\operatorname{POP}_{i, j}}\right)\left(\frac{\operatorname{EDEXP}_{j}}{\sum_{i=1}^{N} \operatorname{POP}_{i, j}}\right)
$$

where $\mathrm{EXPED}_{j}=$ expected public school investment per child in dollars for the $j$ th county; $\mathrm{ENR}_{i, j}=$ number enrolled in school in the $i$ th age group of the $j$ th county; $\operatorname{POP}_{i, j}=$ population in the $i$ th age group of the

20 This problem may not be too severe, given the time-invariant nature of the variables used in the study.

21 This transition does not affect the expected sign of the coefficients, however. The fundamental assumption required is that the parameters are constant over the entire range of the activity in question.

22 One problem with this measure is that desired family size and completed family size may differ. The most often cited example of this is that poorly educated, lowincome households do not have sufficient birth control knowledge to limit children to the desired number. Although this view cannot be ruled out, the regression results offer little support for it.

23 This choice was governed by the fact that this is the oldest age group for which the Census gives children-ever-born figures at the county level in 1960. One might argue, however, that some women in the group may plan to have additional children. If this were particularly true for women who postponed having children in order to participate in another time-intensive activity, attending college, then female education and children-ever-born would exhibit a spurious negative correlation. Fortunately, this does not appear to be true. (See De Tray [1972a] or Sutton and Wunderlich [1967] for evidence supporting this statement.) 
$j$ th county; and $\operatorname{EDEXP}_{j}=$ total public educational expenditures by the $j$ th county. The variable EXPED measures, in dollars, the county public educational investment each child is expected to receive. The first term on the right-hand side is the expected number of years of schooling per child. It is calculated under the assumption that each child of the $i$ th age group who is enrolled in school receives 1 year of schooling for each year the age group spans. The second term is the expected county expenditure on education per child per year. ${ }^{24}$

In theory, enrollment and population for each year, say between the ages of 5 and 19, is required to calculate this measure accurately. In practice, the years were grouped, since the Census does not report enrollment by individual years. ${ }^{25}$

A point of clarification may be necessary here. In the theoretical model, child quality includes all investments in children, whereas the operational measure of that variable appears to capture only those investments that occur outside the home. The assumption implicit in the transition is that total child quality is highly positively correlated with expected public school investment at the county level.

This variable obviously has a number of other shortcomings. The most serious involve the expenditure component. Its political nature will make it suspect for some; it contains both current expenditures and capital investments; it may poorly reflect the quality of education being produced (Welch 1966);26 it fails to capture either private school or college investments in children, two areas where much of the variation in child quality may be occurring. To the extent that these criticisms are valid, they will tend to increase the error with which EXPED measures quality per child. If capital expenditures are randomly distributed among counties, their inclusion in the EXPED variable will reduce the explanatory power of the regressions and increase the standard errors associated with the estimated coefficients. The exclusion of private school and college inputs into the

24 County educational expenditures are calculated from data in the 1962 County and City Data Book (U.S., Bureau of the Census 1962). The data are in the form of total county government expenditures and the percentage of those expenditures classified as educational.

25 The 1960 Census reported enrollment at the county level for the following age groups: 5 and $6,7-13,14$ and 15,16 and 17,18 and 19. Population estimates were available in machine-readable form only in five-year groups except for 14-year-olds. The final formula for each county, therefore, took the following form:

$$
\operatorname{EXPED}=\left[9\left(\frac{\mathrm{ENR}_{5-13}}{\mathrm{POP}_{5-13}}\right)+6\left(\frac{\mathrm{ENR}_{1+-19}}{\mathrm{POP}_{1+-19}}\right)\right]\left(\frac{\mathrm{EDEXP}}{\mathrm{POP}_{5-19}}\right),
$$

where 9 and 6 are the maximum possible years of schooling for each age grouping.

${ }^{26}$ As mentioned earlier, Welch (1966) found that rural schools were often less efficient at producing education than their urban counterparts; thus, higher school expenditures in rural areas did not always mean higher educational output. Since the analysis attempts to remove this rural effect, the problem is somewhat mitigated here. 
educational process will reduce overall variation in EXPED and understate the amount of education received in "high-quality" counties, biasing estimated coefficients toward zero.

The independent variables are more straightforward. ${ }^{27}$ Male and female efficiency parameters, $\beta$ and $\gamma$, are measured by median years of schooling of adults aged 25 and over. Since wage rates by sex are not currently available at the county level, median earnings are used to measure these variables. Male earnings and male wage rates are sufficiently highly correlated, at both the aggregate and the household level, so that earnings are a respectable proxy for wage rates. The same, unfortunately, is not true for female earnings and wages. Smith's (1972a) work points toward.virtually no correlation between wages and earnings for individual women over their lifetimes; however, at the highly aggregate state level, this correlation is almost as strong as that for men. ${ }^{28}$ Even though the state sample should more closely approximate the county sample than the individual data used by Smith, the lack of wage rates by sex is a serious shortcoming of the county data.

A second very serious problem with using observed earnings and even actual wage rates to measure the value of the wife's time in the market place was alluded to in Section II. Neither the level of wages a woman can command in the market place nor, certainly, her market earnings are independent of the number of children she has or wants to have in the future. Thus, as is well known, ordinary least-squares (OLS) regression techniques may yield seriously biased estimates of the impact of female wages on desired children. I attempt to correct this shortcoming of the OLS estimates by using two-stage least-squares (TSLS) techniques, but the results are not encouraging. ${ }^{29}$

Other income ( $V$ in the model) has traditionally been difficult to measure. The Census does not enumerate other income separately but does record median male and female earnings and median income. Unfortunately, since base populations for these figures differ, it is not meaningful either to calculate other income by subtracting earnings from total income ${ }^{30}$ or to enter all three measures in the same regression.

27 One overall shortcoming, however, is that none of the independent variables is age-specific. See De Tray (1972a) for a discussion of this problem. As will be seen, an attempt is made to overcome this problem through two-stage least-squares estimation techniques.

28 The simple correlation for the 48 contiguous states between male earnings and male wages is 0.91 ; that same correlation for women is 0.88 . The wage figures were taken from Social Security full-time (four-quarter) earnings data (U.S., Department of Health, Education and Welfare 1968b).

29 Professor Ashenfelter's comment on this paper was written before the TSLS estimates were available, but $I$ doubt that the gist of his remarks would have changed had he seen them.

30 In fact, this procedure would lead to a negative average value for other income. 
The proxy chosen for other income is the median value of housing in each county. ${ }^{31}$ Housing expenditures and family size may, of course, be related in ways other than through the postulated wealth effect. For example, it could be argued that households with large numbers of children will spend more on housing because they require more space, other things being equal. ${ }^{32} \mathrm{~A}$ positive partial correlation between numbers of children and housing value might therefore stem from this "scale" effect rather than from a positive wealth effect. The available empirical evidence indicates that this is not the case. The results of three separate investigations (Reid 1962; Moeller 1970, p. 83; and De Tray 1972a, p. 57) confirm that expenditures on housing appear to be independent of number of children in the household, when other factors are held constant.

The number of infant deaths per 1,000 live births is included in the regressions to account for exogenous variation in the expected survival rate of children, thus allowing children-ever-born to be interpreted as completed family size.

The last three variables measure the general economic and social structure of each county. They are: percentage of the population living in urban areas, percentage of the population that is rural, and percentage of the population that is nonwhite. The first two are included in an attempt to account for cross-sectional variation in the price of market goods and services; ${ }^{33}$ the last, to account for differences (if any) not captured by the other variables in the economic opportunities and constraints faced by nonwhites.

Table 1 contains a description of the variables, table 2 has summary statistics, and table 3 gives weighted summary statistics. Table 4 is a simple correlation matrix for the variables. The "weighted" means and standard deviations are based on the original sample weighted by the square root of the female population aged $35-44 .^{34}$

31 Median value of housing and median income are highly correlated: the simple correlation between these variables for this sample is 0.82 .

32 Of course, "more space" and "larger housing expenditures" are not synonymous terms. In order to increase their physical living space, families may reduce the overall quality of their housing, thus keeping housing expenditures constant.

33 Two measures of "ruralness" were used originally, one being percentage of the population classified as rural farm, and the other, the percentage of the employed population working in agriculture. Initial estimates contained only the rural-farm measure. A problem of interpretation arose with this variable in that any increase in the percentage of the population classified as rural farm while holding constant percentage of the population classified as urban implies that the only remaining sector, percentage rural nonfarm, must be decreasing. However, since both measures performed very similarly, only the rural-farm results are reported here.

34 The weighting factors are chosen so that the moment matrix will be weighted by the denominator of the dependent variable. Since both weighting factors (women aged $35-44$ and population aged 5-19) yield similar weighted summary statistics, only one set is presented. 
TABLE 1

The Regression Variables

\begin{tabular}{|c|c|c|}
\hline $\begin{array}{l}\text { Variable } \\
\text { Name }\end{array}$ & $\begin{array}{l}\text { Conceptual } \\
\text { Equivalent }\end{array}$ & Description \\
\hline CEB35* ... & $N$ & $\begin{array}{l}\text { Children-ever-born per } 1,000 \text { married wo- } \\
\text { men aged } 35-44 \text {, in } 1960\end{array}$ \\
\hline EXPED* .. & $Q / N$ & $\begin{array}{l}\text { Expected public school investment per child } \\
\text { (\$) (see text for formula), } 1960\end{array}$ \\
\hline EDM & $\beta$ & $\begin{array}{l}\text { Median years of schooling for men aged } \\
25+, 1960\end{array}$ \\
\hline EDF & $\gamma$ & $\begin{array}{l}\text { Median years of schooling for women, aged } \\
25+, 1960\end{array}$ \\
\hline MALEARN* & $W_{m}$ & $\begin{array}{l}\text { Median earnings ( } \$ \text { ) of males who had } \\
\text { earnings in } 1959\end{array}$ \\
\hline FEMEARN* & $W_{1}$ & $\begin{array}{l}\text { Median earnings (\$) of women who had } \\
\text { earnings in } 1959\end{array}$ \\
\hline HSEVAL* & $I$ & Median value of housing (\$), 1960 \\
\hline INFDTH $\ldots \ldots$ & $\ldots$ & Infant deaths per 1,000 live births, 1960 \\
\hline URBAN $\ldots$ & $P_{N} / P_{Q}$ & $\begin{array}{l}\text { Population }(\%) \text { living in towns of } 2,500 \\
\text { inhabitants or more, } 1960\end{array}$ \\
\hline RURAL & $P_{Q} / P_{N}$ & Population (\%) living on farms, 1960 \\
\hline RACE & $\cdots$ & Population (\%) nonwhite, 1960 \\
\hline
\end{tabular}

* Variable entered in $\log$ form.

\section{The Results ${ }^{35}$}

The results of the regression analysis are presented in table 5 . As the model of Section II indicates, the two dependent variables, children-everborn and the expected schooling investment per child, as well as all mea-

TABLE 2

SUMMARY STATISTICS

\begin{tabular}{|c|c|c|c|c|}
\hline Variable & Mean & SD & Minimum & Maximum \\
\hline CEB 35 & $3,116.3$ & 568.6 & $1,962.0$ & $5,346.0$ \\
\hline EXPED & $2,758.3$ & $1,180.0$ & 323.0 & $8,872.1$ \\
\hline EDM . & 9.11 & 1.44 & 4.9 & 12.6 \\
\hline EDF & 9.98 & 1.52 & 5.7 & 12.6 \\
\hline MALEARN & $3,366.1$ & $1,119.6$ & 913.0 & $6,546.0$ \\
\hline FEMEARN & $1,575.0$ & 517.4 & 442.0 & $3,343.0$ \\
\hline HSEVAL . & $8,014.1$ & $2,882.9$ & $5,000.0$ & $20,200.0$ \\
\hline INFDTH & 27.5 & 11.4 & 0.0 & 72.5 \\
\hline URBAN $\ldots \ldots \ldots \ldots$ & 34.0 & 27.6 & 0.0 & 100.0 \\
\hline RURAL $\ldots \ldots \ldots \ldots \ldots$ & 21.6 & 15.3 & 0.0 & 67.2 \\
\hline $\operatorname{RACE} \ldots \ldots \ldots \ldots$ & 11.4 & 17.4 & 0.0 & 76.0 \\
\hline
\end{tabular}

35 An analysis of the residuals of the two sets of regressions was also undertaken. The results indicate no particular underlying relationship between the CEB.35 and the EXPED regressions (see De Tray 1972a). 
TABLE 3

Weichted Summary Statistics

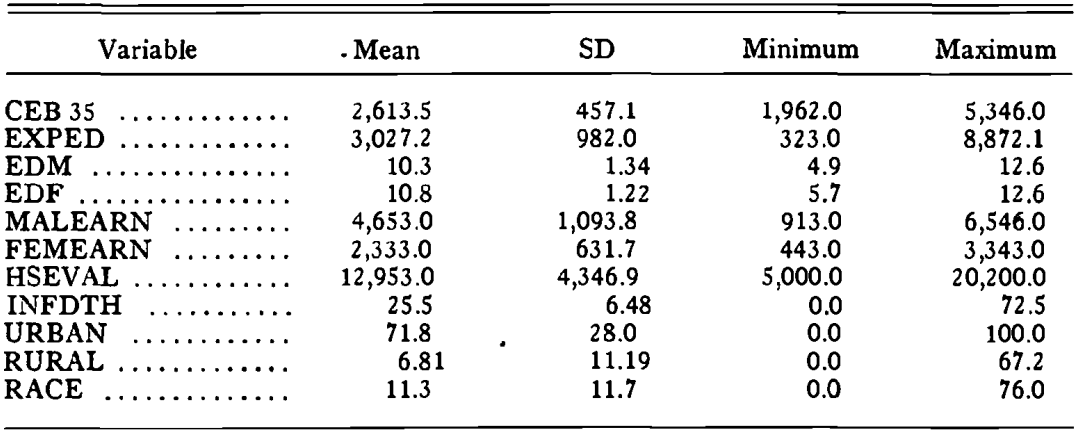

NotE.-Each observation is weighted by the square root of the female population aged 35-44.

TABLE 4

Simple Correiation Matrix

\begin{tabular}{|c|c|c|c|c|c|}
\hline Variable & EXPED & EDM & EDF & MALEARN & FEMEARN \\
\hline CEB 35 & -0.28 & -0.60 & -0.53 & -0.58 & -0.63 \\
\hline EXPED & $\ldots$ & 0.43 & 0.55 & 0.48 & 0.25 \\
\hline EDM & $\ldots$ & $\ldots$ & 0.91 & 0.81 & 0.58 \\
\hline EDF & $\ldots$ & $\ldots$ & $\ldots$ & 0.73 & 0.46 \\
\hline MALEARN & $\ldots$ & $\ldots$ & $\ldots$ & $\ldots$ & 0.74 \\
\hline FEMEARN .. & $\ldots$ & $\ldots$ & $\ldots$ & $\ldots$ & $\ldots$ \\
\hline HSEVAL $\ldots$. & $\ldots$ & $\ldots$ & $\ldots$ & $\ldots$ & $\ldots$ \\
\hline INFDTH $\ldots$. & $\ldots$ & $\ldots$ & $\ldots$ & $\ldots$ & $\ldots$ \\
\hline URBAN $\ldots$. & $\ldots$ & $\ldots$ & $\ldots$ & $\ldots$ & $\ldots$ \\
\hline RURAL $\ldots \ldots$ & $\ldots$ & $\ldots$ & $\cdots$ & $\ldots$ & $\ldots$ \\
\hline
\end{tabular}

TABLE 4 (Continued)

\begin{tabular}{|c|c|c|c|c|c|}
\hline Variable & HSEVAL & INFDTH & URBAN & RURAL & RACE \\
\hline $\begin{array}{l}\text { CEB } 35 \ldots \ldots \\
\text { EXPED } \ldots \ldots \\
\text { EDM } \ldots \ldots \\
\text { EDF } \ldots \ldots \\
\text { MALEARN } \ldots \\
\text { FEMEARN } \ldots \\
\text { HSEVAL } \ldots . \\
\text { INFDTH } \ldots \ldots \\
\text { URBAN } \ldots \ldots \\
\text { RURAL } \ldots . .\end{array}$ & $\begin{array}{r}-0.45 \\
0.25 \\
0.71 \\
0.62 \\
0.76 \\
0.64 \\
\ldots \\
\ldots \\
\ldots \\
\ldots\end{array}$ & $\begin{array}{r}0.33 \\
-0.29 \\
-0.37 \\
-0.38 \\
-0.33 \\
-0.27 \\
-0.24 \\
\ldots \\
\ldots \\
\ldots\end{array}$ & $\begin{array}{r}-0.43 \\
0.07 \\
0.49 \\
0.36 \\
0.60 \\
0.49 \\
0.64 \\
-0.05 \\
\ldots \\
\ldots\end{array}$ & $\begin{array}{r}0.36 \\
-0.06 \\
-0.39 \\
-0.24 \\
-0.61 \\
-0.50 \\
-0.46 \\
-0.03 \\
-0.61 \\
\ldots\end{array}$ & $\begin{array}{r}0.43 \\
-0.41 \\
-0.51 \\
-0.49 \\
-0.49 \\
-0.43 \\
-0.22 \\
0.49 \\
-0.09 \\
0.05\end{array}$ \\
\hline
\end{tabular}


TABLE 5

THE RECRESSION Results

\begin{tabular}{|c|c|c|c|c|}
\hline \multirow[b]{3}{*}{ INDEPENDENT VABIABLE* } & \multicolumn{4}{|c|}{ DEPENDENT VARIABLE } \\
\hline & \multicolumn{2}{|c|}{ CEB35† } & \multicolumn{2}{|c|}{ EXPED $\dagger$} \\
\hline & OLS $\ddagger$ & TSLS & OLS§ & TSLS\& \\
\hline $\begin{array}{l}\text { EDM: median years of } \\
\text { schooling, male } \ldots \ldots \ldots \ldots \ldots\end{array}$ & $\begin{array}{l}0.0077 \\
(0.74)\end{array}$ & $\begin{array}{l}0.0046 \\
(0.28)\end{array}$ & $\begin{array}{r}-0.068 \\
(1.77)\end{array}$ & $\begin{array}{r}-0.064 \\
(1.51)\end{array}$ \\
\hline $\begin{array}{l}\text { EDF: median years of } \\
\text { schooling, female } \ldots \ldots \ldots \ldots\end{array}$ & $\begin{array}{r}-0.030 \\
(3.19) \\
{[0.32]}\end{array}$ & $\begin{array}{r}-0.060 \\
(4.23) \\
{[0.64]}\end{array}$ & $\begin{array}{r}0.092 \\
(2.65) \\
{[0.99]}\end{array}$ & $\begin{array}{l}0.11 \\
\cdot(2.84) \\
{[1.2]}\end{array}$ \\
\hline $\begin{array}{l}\text { HSEVAL: } \text { median value of } \\
\text { housing } \dagger \ldots \ldots \ldots \ldots \ldots \ldots\end{array}$ & $\begin{array}{r}0.065 \\
(2.73) \\
{[0.07]}\end{array}$ & $\begin{array}{l}0.39 \\
(6.12) \\
{[0.39]}\end{array}$ & $\begin{array}{c}0.073 \\
(0.81) \\
\ldots\end{array}$ & $\begin{array}{c}0.28 \\
(1.58) \\
\ldots\end{array}$ \\
\hline $\begin{array}{l}\text { MALEARN: median earnings, } \\
\text { malet } \ldots \ldots \ldots \ldots \ldots \ldots \ldots \ldots \ldots\end{array}$ & $\begin{array}{r}0.074 \\
(2.12) \\
{[0.07]}\end{array}$ & $\begin{array}{l}0.28 \\
(3.27) \\
{[0.23]}\end{array}$ & $\begin{array}{l}0.90 \\
(6.96) \\
{[0.9]}\end{array}$ & $\begin{array}{c}0.37 \\
(1.56) \\
\cdots\end{array}$ \\
\hline $\begin{array}{l}\text { FEMEARN: median earnings, } \\
\text { female } \dagger \ldots \ldots \ldots \ldots \ldots \ldots \ldots\end{array}$ & $\begin{array}{l}-0.30 \\
(12.5) \\
{[0.30]}\end{array}$ & $\begin{array}{l}-0.86 \\
(13.2) \\
{[0.86]}\end{array}$ & $\begin{array}{c}-0.11 \\
(1.23) \\
\ldots\end{array}$ & $\begin{array}{c}-0.11 \\
(0.67) \\
\cdots\end{array}$ \\
\hline INFDTH: infant death rate $\ldots$ & $\begin{array}{l}0.0009 \\
(1.24) \\
\cdots\end{array}$ & $\begin{array}{l}0.0010 \\
(0.94) \\
\cdots\end{array}$ & $\begin{array}{l}-0.0048 \\
(1.95) \\
{[0.12]}\end{array}$ & $\begin{array}{l}-0.0060 \\
(2.28) \\
{[0.15]}\end{array}$ \\
\hline URBAN: $\%$ urban $\ldots \ldots \ldots \ldots$ & $\begin{array}{l}-0.0022 \\
(7.69) \\
{[0.16]}\end{array}$ & $\begin{array}{l}-0.0027 \\
(5.54) \\
{[0.17]}\end{array}$ & $\begin{array}{c}-0.0001 \\
(0.09) \\
\ldots\end{array}$ & $\begin{array}{c}-0.0003 \\
(0.22) \\
\cdots\end{array}$ \\
\hline RURAL: \% rural-farm $\ldots \ldots \ldots$ & $\begin{array}{l}0.0011 \\
(1.74)\end{array}$ & $\begin{array}{c}-0.0015 \\
(1.34) \\
\cdots\end{array}$ & $\begin{array}{l}0.0070 \\
(3.04) \\
{[0.05]}\end{array}$ & $\begin{array}{l}0.0015 \\
(0.50) \\
\quad \ldots\end{array}$ \\
\hline RACE: \% nonwhite $\ldots \ldots \ldots \ldots$ & $\begin{array}{l}-0.0005 \\
(1.12)\end{array}$ & $\begin{array}{l}-0.0037 \\
(4.44)\end{array}$ & $\begin{array}{l}-0.0027 \\
(1.67)\end{array}$ & $\begin{array}{l}-0.0060 \\
(2.74)\end{array}$ \\
\hline CONSTANT $\ldots \ldots \ldots \ldots \ldots \ldots$ & $\begin{array}{r}9.33 \\
(41.1) \\
\end{array}$ & $\begin{array}{r}9.38 \\
(19.8) \\
\end{array}$ & $\begin{array}{r}0.347 \\
(0.41) \\
\end{array}$ & $\begin{array}{c}2.88 \\
(2.20) \\
\end{array}$ \\
\hline 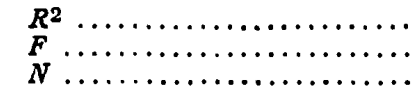 & $\begin{array}{l}0.75 \\
169 \\
516\end{array}$ & $\begin{array}{l}10.83 \\
516\end{array}$ & $\begin{array}{l}0.47 \\
51.1 \\
527\end{array}$ & 527 \\
\hline
\end{tabular}

- For description of variables, see table $1: t$-ratios given in parentheses; elasticity at mean given in brackets (absolute value; given only for coeficients with $t$-ratios $\triangleq 1.95$ ).

$\dagger$ Variable enters regressions in log form.

F Weighted by square root of female population. ages 35 to 44 .

$\$$ Weighted by square root of population, ages 5 to 19 .

sures of earnings and full wealth, are used in $\log$ form. Following Mincer's work, ${ }^{36}$ years of schooling for men and women enter as normal numbers, as do infant deaths and the three measures of county characteristics, percentage of the population urban, rural, and nonwhite.

${ }^{30}$ See, e.g., Mincer (1974a), where he summarizes much of his previous published and unpublished work and once again states the rationale for using years of schooling rather than the log of that number in equations explaining wage differences. 
For comparison, TSLS estimates treating male and female earnings and house value as endogenous are also given in this table. ${ }^{37}$ These results do not appear to solve the simultaneous-bias problem as had originally been hoped.

\section{Numbers of Children (CEB35)}

The OLS coefficients for the CEB35 regressions are remarkably strong, especially in view of the severe multicollinearity among the variables. ${ }^{38}$ The statistically weakest coefficient is that for male education. This may be partly because of the close correlation of this variable with both female education and male earnings; it may also indicate that with earnings, full wealth, and female education held constant, changes in male education have little effect on numbers of children. The female education coefficient is strongly negative, with an elasticity at the mean of approximately -0.3 . In the past it has been argued that education is a proxy for either price of time (female education) or permanent wealth (male education), or that education captures differences in contraceptive knowledge. With respect to the first of these, an attempt has been made to remove wealth and timeprice effects. The continued existence of a significant negative coefficient for female education and a very weak positive coefficient for male education indicates that these variables may have effects on numbers of children that are not associated with either wealth or relative prices. This result is consistent with the earlier contention that increasing female education increases the efficiency with which child quality can be produced but has little effect on the production technology of numbers of children.

The alternative education-contraception hypothesis is difficult to disprove, particularly in aggregate data such as these. It is my opinion, based on my own work and that of others, that the strength of the femaleeducation coefficient is not attributable to differences in contraceptive knowledge across the U.S. population, but the case is far from proven either way.

Increases in median value of housing have a small but significant positive effect on CEB35. In her housing-income study Reid (1962) found the pure income elasticity for housing expenditures to be around 2.0. If this latter measure is taken as correct, the HSEVAL coefficient implies on

${ }^{37}$ See $n .29$ in this regard. The excluded "exogenous" variables are percentage of the population with less than 5 years of schooling and with 12 years or more of schooling (educational distribution parameters), percentage of the population in different age categories (21-plus and over 65), median age of population, and several measures of parent background such as percentage foreign born and percentage whose parents were foreign born.

38 The various tests for multicollinearity suggested in Farrar and Glauber (1967) were applied to the regressions. The worst problem occurred, as one might suspect, between male and female education. 
the average an income (full-wealth) elasticity for numbers of children of 0.12 .

Although the simple correlation between male and female earnings is quite high (0.73), the effects of these variables on CEB35 differ considerably. An increase in male earnings has a positive effect on children-everborn, but an increase in female earnings has a strong negative effect. Elasticities associated with these variables are 0.09 for male earnings and -0.30 for female earnings. These results are consistent with previous findings and my discussion of these variables above. Numbers of children, as well as child services in general, have long been assumed to be female time-intensive; therefore, an increase in the price of female time causes households to substitute away from both numbers of children and child services. ${ }^{39}$ If the opposite is true for men, that is, that the share of male time in the production of both $N$ and $C$ is small relative to the share of male time in other household commodities $(Z)$, then an increase in the price of male time will bring about a substitution toward both $N$ and $C$.

The coefficient of the infant-death-rate variable is never significantly different from zero. In part, this may be due to the offsetting effects associated with this variable (see discussion above).$^{40}$

The variables URBAN and RURAL behave as predicted under the assumption that they measure variations in the price of market goods and services. An increase in percentage urban lowers the desired number of children, "but a similar change in percentage rural increases the desired number of children.

In the past, demographers and sociologists have implied that nonwhites produce more children than whites, other things being equal. The coefficient for RACE contradicts this belief ${ }^{41}$ If education levels and earnings are held constant, increasing the percentage nonwhite in a country has, if anything, a weak negative effect on children-ever-born.

Table 6 illustrates the reasonable magnitude of effects on predicted numbers of children-ever-born associated with plausible changes in certain variables. ${ }^{42}$ If the OLS estimates are valid, a rather strong assumption

\footnotetext{
${ }^{39}$ Again, the reader must be cautioned about the simultaneous nature of the female-earnings variable. The OLS regression technique used in this report is not capable of distinguishing the effect of earnings on desired children from that of children on female earnings. Therefore, this coefficient may contain a serious simultaneous bias. The degree to which the TSLS estimates solve this problem is discussed later in the text.

40 It may also reflect the fact that the expected infant mortality rates on which women 40 years old in 1960 based their fertility decisions were those of 1940 or so, not those of 1960 .

41 However, see Gardner's paper in this book for evidence that contradicts this finding.

42 The choice of the "plausible changes" was not entirely arbitrary. In each case, the 1960 values for the variables were increased or decreased by the percentage change for comparable variables between 1950 and 1960; thus, the "prediction" is for decen-
} 
TABLE 6

Predicted Decennial Change in Children-Ever-Born per Woman Aged 35-44

\begin{tabular}{|c|c|}
\hline Initial predicted value $(1960)^{*}$ & 2.66 children-ever-born \\
\hline \multicolumn{2}{|l|}{ Changes in exogenous variables: $\dagger$} \\
\hline 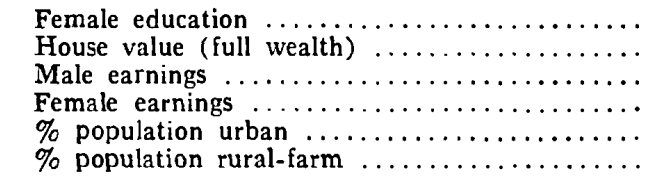 & $\begin{array}{l}+14 \% \\
+39 \% \ddagger \\
+43 \% \ddagger \\
+42 \% \ddagger \\
+12 \% \\
-55 \%\end{array}$ \\
\hline $\begin{array}{l}\text { New predicted value* } \ldots \ldots \ldots \ldots \ldots \ldots \\
\text { Change in childen-ever-born } \ldots \ldots \ldots \ldots\end{array}$ & $\begin{array}{l}2.36 \text { children-ever-born } \\
-11.5 \%\end{array}$ \\
\hline
\end{tabular}

* Calculated using first two significant digits of OLS coefficient only. TSLS estimates yielded similar net results even though individual coefficients differ.

$t$ Based on 1950-60 changes for comparable variables.

$\ddagger$ Represent real, not nominal, changes.

given the inadequacies of the data, zero population growth is, so to speak, just around the corner. The postulated changes in the variables indicate a reduction in predicted family size from 2.7 children per woman to 2.4 over a 10-year period.

\section{Quality per Child (EXPED)}

The proxy chosen for quality per child (EXPED) is an admittedly crude first attempt to quantify that potentially important variable. The results of the regressions on public school expenditures should, therefore, be viewed with much more skepticism than those for the number of children. It seems likely that problems caused by the level of aggregation and simultaneous bias may be even more severe than those encountered in the CEB35 results. Finally, even though the EXPED regressions are open to several alternative, and reasonably plausible, explanations, they will be discussed as if the proxy variables do measure what they are supposed to measure.

Male education (EDM) and percentage of the population rural (RURAL) exhibit what appears to be anomalous behavior. The maleeducation coefficient is insignificant or negative, implying that either (1) the effects of that variable are approximately the same both for numbers of children and for child quality, or (2) if anything, male education contributes more to the production efficiency of numbers of children than to the efficiency with which child quality is produced.

As for the RURAL measure, it was argued during the discussion of the CEB35 results that URBAN and RURAL captured cross-sectional variation in the price of market goods and services. Implicit in this statement is

nial, not annual, changes in the variables. Note that only those variables with statistically significant coefficients were changed. 
the presumption that in rural counties those market goods and services that are primary inputs into numbers of children will be cheap relative to goods and services entering child-quality production. This, in turn, implies that the coefficient for RURAL in the EXPED regressions should be negative; in fact, this coefficient is strongly positive.

Part of the solution of this puzzle may be found in Welch's (1966) work on quality in education, where he observes that educational expenditures are, in and of themselves, poor indicators of the quality of education being produced by schools. He attributes this to the existence of "economies of scale" in the educational process. In essence, his argument is that schools in sparsely populated areas suffer because their facilities fall well below the optimal size. ${ }^{43}$ If this is true, rural areas are likely to receive less education per dollar expenditure than more densely populated urban areas.

These scale effects will at minimum cause EXPED to overestimate quality per child in rural areas. The positive coefficient for RURAL may be a result of this latter phenomenon plus the fact that education, earnings, and income are being held constant. In other words, if the rural population has tastes similar to those of the urban population for quality per child as measured by EXPED, then, with prices and income held constant, rural counties are likely to have relatively high educational expenditures per eligible population to partly offset the inefficiencies of their school systems.

Female education has a strong positive sign, as would be expected from the earlier efficiency arguments and the partial correlation of female education in the children-ever-born regressions. Since quality does not appear to be particularly female time-intensive compared with numbers of children (the OLS coefficient for female earnings is not significant in the EXPED regression), this finding lends support to the "efficiency" (as opposed to time-intensity) explanation of the observed differences by educational class in female labor-force participation.

It is tempting to interpret the insignificant coefficients for HSEVAL as indicating that derived income elasticities for $Q$ (total quality in children) and for $N$ (numbers of children) are equal in size. ${ }^{44}$ This interpretation supports the quantity-quality substitution hypothesis and the particular functional forms chosen for the model. Indeed, it is surprising that EXPED and HSEVAL are not positively related if for no other reason than that school expenditures are usually derived from property taxes. However, it is always difficult to attach precise meaning to insignificant coefficients: therefore, this finding must be viewed with considerable caution.

\footnotetext{
43 Also, Welch points out that a significant fraction of rural educational expenditures went for transportation, which, again, implies that rural school dollars "buy" less education than urban school dollars.

44 That is, EXPED is a proxy of $Q / N$ (the relative amount of $Q$ to $N$ ), which is invariant with respect to scale (nonwage income) effects.
} 
As in the CEB35 regression, male and female earnings have very different effects on quality per child. The strength and size of the positive maleearnings coefficient make its theoretical interpretation suspect. According to theory, this result implies that male time is used more heavily in quantity than in quality production.

The strong negative coefficient for infant death rates is consistent with the theory that the higher the probability of a child's dying, the less likely parents are to invest large amounts of resources in that child (see O'Hara 1972). The statistical strength of this coefficient may also be a function of the fact that the rate at which infants survive is not, as has been traditionally assumed, always exogenous to household decisions. The more resources invested in a child, the more likely that child is to survive. But the more resources a household invests in children, the higher the "quality" of those children. Thus infant mortality and expected school expenditures may both measure child quality; it is not surprising, therefore, that they are strongly related.

\section{TSLS Estimates}

One question is why I concentrate on OLS results when TSLS estimates should yield less biased coefficients. One simple answer is that my two-stage estimates are not included in this paper. A second more substantive reason is that for these data the TSLS, techniques apparently do not do what they were expected to do, that is, solve the simultaneous-bias problem. If an OLS estimate of, say, the impact of female earnings on children-ever-born seriously overstates the size of that effect, then TSLS techniques should produce a reduced estimate of the female-earnings coefficient. As equation (2) confirms, female earnings have a larger impact on numbers of children in the TSLS regressions than in the OLS results. It seems likely, then, that the TSLS procedures simply yield more error-free measures of the included endogenous variables, but do little to reduce simultaneous bias.

\section{Summary of Empirical Results}

Both sets of regressions (CEB35 and EXPED) imply that production of child services is dominated by women. The role of men seems to be primarily as suppliers of market goods and services, but this part of the picture is still unclear.

Female earnings are the single most important factor in the completedfamily-size regressions in terms of both magnitude of effect and statistical significance. Other variables having a significant negative effect on childrenever-born are female education and the degree to which a county is urban. On the other hand, median value of housing as a proxy for full wealth and male earnings exerts a positive influence on desired numbers of children. 
In addition, the children-ever-born regressions indicate that (1) the fullwealth elasticity for numbers of children is probably positive but small, and (2) when economic differences are accounted for, race may play virtually no role in determining family size.

The regressions on quality per child are weaker than those for numbers of children. In part, this must stem from the proxy variable used in the regressions (expected county public school investment), which undoubtedly contains large errors of measurement. The very tentative findings from these regressions are, first, that female education increases the relative efficiency with which child quality is produced, thereby reducing its effective real price, and, second, that the derived income elasticities for numbers of children and for child quality appear to be equal. Also, although it is not a prediction of the theory, the behavior of the rural and race measures is consistent with the hypothesis that there is little difference in "tastes" for child quality either between rural and urban residents or between whites and nonwhites, other things being equal.

\section{Appendix}

\section{Derivation of the Model ${ }^{45}$}

Let the household utility function be represented by

$$
U=U(C, Z)
$$

where $C$ is child services and $Z$ is everything else. Production functions for $C$ and $Z$ are assumed to be linear homogeneous, with average costs of $\pi_{C}$ and $\pi_{Z}$, respectively. The household budget constraint may then be written as

$$
I=\pi_{z} \cdot Z+\pi_{C} \cdot C,
$$

where $R$ is a measure of the household's full wealth. Under the assumptions of linear homogeneity, changes in the demand for $C$ can be written

$$
E C=\eta E I-[k \eta+(1-k) \sigma] E \pi_{c}+(1-k)(\sigma-\eta) E \pi_{z}
$$

where the $E$ operator denotes percentage change (for example, $E C=d[\log C]$ $=[1 / C] d C) ; \eta$ is the income (wealth) elasticity of the demand for $C ; \sigma$ is the elasticity of substitution between $C$ and $Z$ in $U(C, Z)$; and $k$ is the share of full wealth spent on $C\left(=\left[\pi_{C} \cdot C\right] / I\right)$.

The production function for $C$ takes the form

$$
C=C(Q, N)
$$

where $Q=$ child-quality input and $N=$ child-body input. Since equation (A4) is linear homogeneous,

$$
E \pi_{c}=\alpha E \pi_{N}+(1-\alpha) E \pi_{Q},
$$

where $\pi_{Q}=$ per-unit "rent" of the stock of quality, $Q ; \pi_{N}=$ per-unit "rent" of the stock of child bodies, $N$; and $\alpha=\pi_{N} \cdot N / \pi_{C} \cdot C$.

45 Professor $H$. Gregg Lewis first put me on this particular tack and supplied an outline of the derivation. 
From the definition of the elasticity of substitution between two factors of production and from the fact that in equilibrium $\left(\pi_{N}\right) /\left(\pi_{Q}\right)=M P_{N} / M P_{Q}$ (the ratio of the prices of $N$ and $Q$ must equal the ratio of their respective marginal products in the production of $C$ ),

$$
E C-E N=\sigma^{*}\left(E \pi_{N}-E \pi_{C}\right),
$$

where $\sigma^{*}=$ elasticity of substitution between $N$ and $Q$ in the production of $C$. Therefore, from (A3), (A5), and (A6),

$$
\begin{aligned}
E N=\eta E I & -\left\{\alpha[k \eta+(1-k) \sigma]+(1-\alpha) \sigma^{*}\right\} E \pi_{N} \\
& +(1-\alpha)\left[\sigma^{*}-k \eta-(1-k) \sigma\right] E \pi_{Q} \\
& +(1-k)(\sigma-\eta) E \pi_{Z} .
\end{aligned}
$$

Full wealth is defined as

$$
I=V+W^{*}{ }_{m}+W^{*},
$$

where $V=$ property wealth, $W^{*}$ = lifetime possible wage earnings of the female $\left(T_{f} \cdot W_{f}\right)$, and $W^{*}{ }_{m}=$ lifetime possible wage earnings of the male $\left(T_{m} \cdot W_{m}\right)$. From equation (A8),

$$
E I=\frac{V}{I} E V+\frac{W^{*}}{I} E W^{*},+\frac{W^{*}{ }_{m}}{I} E W^{*}{ }_{m} .
$$

Again, the $E$ operator signifies percentage change.

As with $C$, the production functions for $N, Q$, and $Z$ are linear homogeneous; each takes as inputs three factors, that is,

$$
\begin{aligned}
& Q=Q\left(t_{m . Q}, t_{f, Q}, X_{Q} ; \beta, \gamma\right), \\
& N=N\left(t_{m, N}, t_{f . N}, X_{N} ; \beta, \gamma\right), \\
& Z=Z\left(t_{m, Z}, t_{f, Z}, x_{Z} ; \beta, \gamma\right),
\end{aligned}
$$

where $t_{m, N}, t_{m, Q}$, and $t_{m, Z}$ are time of male in the production of $N, Q$, and $Z$, respectively, and $t_{f . N}, t_{f, Q}$, and $t_{f . Z}$ are market-goods inputs into the production of $N, Q$, and $Z$. The environmental variables $\beta$ and $\gamma$ represent the husband's and the wife's "quality," respectively, and are a function of the amount of formal schooling each has received. The male's time has a price of $W_{m}$; the female's time, a price of $W_{f}$; and the market goods have prices of $P_{N}, P_{Q}$, and $P_{Z}$, respectively. From these equations it follows that

$$
\begin{aligned}
& E \pi_{N}=\alpha_{t_{m, N}} E W_{m}+\alpha_{t_{f, N}} E W_{f}+\alpha_{x_{N}} E P_{N}-\mu_{N, \beta} E \beta-\mu_{N, \gamma} E \gamma ; \\
& E \pi_{Q}=\alpha_{t_{m, Q}} E W_{m}+\alpha_{t_{f, Q}} E W_{f}+\alpha_{X_{Q}} E P_{Q}-\mu_{Q, \beta} E \beta-\mu_{Q, \gamma} E \gamma \\
& E \pi_{z}=\alpha_{t_{m, Z}} E W_{m}+\alpha_{t_{f, Z}} E W_{f}+\alpha_{X_{Z}} E P_{z}-\mu_{z, \beta} E \beta-\mu_{Z, \gamma} E \gamma,
\end{aligned}
$$

where $\left.\alpha_{t_{m, N}}=\left(t_{m, N} \cdot W_{m}\right) / \pi_{N} \cdot N\right)$ and the other $\alpha$ 's are similarly defined, and $\mu_{N . \beta}$ is the partial elasticity of $N$ with respect to $\beta$, with similar definitions for the other $\mu$ 's. 
Now, combining (A9) and (A11) with (A7), the following expression for the percentage change in $N$ is obtained:

$$
\begin{aligned}
E N & =(V / I) \eta E V \\
& -\alpha_{x_{N}}\left\{\alpha[k \eta+(1-k) \sigma]+(1-\alpha) \sigma^{*}\right\} E P_{N} \\
& +\alpha_{x_{Q}}(1-\alpha)\left[\sigma^{*}-k \eta-(1-k) \sigma\right] E P_{Q} \\
& +\alpha_{x_{Z}}(1-k)(\sigma-\eta) E P_{Z} \\
& +\left[(1-\alpha) \sigma^{*}\left(\alpha_{t_{m, Q}}-\alpha_{t_{m, N}}\right)+(1-k) \sigma\left(\alpha_{t_{m, Z}}-\alpha_{t_{m, C}}\right)\right. \\
& \left.+\left(Y_{m} / I\right) \eta\right] E W_{m} \\
& +\left[(1-\alpha) \sigma^{*}\left(\alpha_{t_{f, Q}}-\alpha_{t_{f, N}}\right)+(1-k) \sigma\left(\alpha_{t_{f, Z}}-\alpha_{t_{f, C}}\right)\right. \\
& +\left\{(1-\alpha) \sigma^{*}\left(\mu_{N, \beta}-\mu_{Q, \beta}\right)+(1-k) \sigma\left(\mu_{C, \beta}-\mu_{Z, \beta}\right)\right. \\
& \left.+\eta\left[k \mu_{C, \beta}+(1-k) \mu_{Z, \beta}\right]\right\} E \beta \\
& +\left\{(1-\alpha) \sigma^{*}\left(\mu_{N, \gamma}-\mu_{Q, \gamma}\right)+(1-k) \sigma\left(\mu_{C, \gamma}-\mu_{Z, \gamma}\right)\right. \\
& \left.+\eta\left[k \mu_{C, \gamma}+(1-k) \mu_{Z, \gamma}\right]\right\} E \gamma .
\end{aligned}
$$

In order to ease the reader's task, nonmnemonic symbols all will be defined here:

$$
\begin{aligned}
& E=d(\log ) \text { operator (percentage change); } \\
& V=\text { non-wage-related income; } \\
& I \text { = full wealth; } \\
& \eta=\text { income elasticity of } C \text {, child services; } \\
& \alpha=\text { the share of expenditures on } N \text { in total expenditures on } C \text {, that } \\
& \text { is, }\left(\pi_{N} \cdot N\right) / \pi_{C} \cdot C \text {; } \\
& \sigma^{*}=\text { the elasticity of substitution between } N \text { and } Q \text { in the production } \\
& k=\text { the share of total expenditures on } C \text { in full wealth, } I \text {; } \\
& \sigma=\text { substitution elasticity between } C \text { and } Z \text { in } U(C, Z) \text {; } \\
& P_{i}=\text { price of market goods and services } X_{i} \text {; } \\
& Y_{i}=\text { lifetime market earnings of the } i \text { th household member, } i=m, f \text {; } \\
& W_{i}=\text { wage rate of } i \text { th household member; and } \\
& \mu_{i, j}=\text { the partial elasticity of the } i \text { th output with respect to the educa- }
\end{aligned}
$$




\title{
Comment
}

\section{Orley Ashenfelter}

\author{
Princeton University
}

When an important social issue emerges that does not fall into the traditional domain of economic analysis, there is always some uneasiness about the usefulness of economists' applying their tools in the new domain. Since I believe that economic tools are useful in the analysis of social problems, it is my own view that it is important for economists' methods to be extended into these "nontraditional" fields as far as possible, and I interpret the works of Becker and Mincer cited so frequently throughout this conference as among the original efforts to do this. Moreover, in a subject as important as the economic determinants of fertility control, I find somewhat shortsighted the comments of those economists who argue that the explanations for most of the variation in birth rates or family size are noneconomic or sociological factors. For even if it is true that the historical explained variance for economic variables is small, this position ignores the fact that most of the social programs of interest to economists in recent years-including negative income taxes, demo-grants, and housing allowances-change the income and effective wage rates that many families in some economic strata will face, and that any careful analysis of the social and economic consequences of these programs should include an objective appraisal of their long-run effects on population size. The ability to obtain such an appraisal is presumably the long-run goal of the economic analysis of population.

At the same time, it seems important to me that when economic tools are applied in unfamiliar terrain, the work should be done with special clarity and without any exaggeration of their power to obtain rigorous predictions concerning observable variables. In addition, our standards for evidence regarding the validity of hypotheses should, if anything, be stronger than in more traditional areas. On both of these grounds Dennis De Tray's paper leaves something to be desired.

As to the underlying theory, it is essentially an application of the 
classical theory of consumer choice to the demand for children. In order to test the usefulness of this theory, one presumably should first clarify its implications, which, though limited, are nevertheless powerful, even in this case. On the one hand, for example, one could observe the demand for some commodity that is clearly and directly related to childbearing, as, for example, the cost of maternity services, and estimate the incomecompensated effect of a change in the price of these services on the demand for them, which the theory would predict is negative. Alternatively, one could observe the demand for two goods or services thought to be related in utility to the demand for children in order to test whether the income-compensated cross-price effects were equal, which is also an unambiguous prediction from the theory. Instead, De Tray attempts to determine the empirical importance of changes in the wage rate of the wife on the demand for children, following up the interesting observation by several economists that the wife's nonmarket time and the family's demand for children may be economic complements. Unfortunately, unless we assume that all of the wife's nonmarket time must be used for child rearing, we cannot predict that complementarity will be the case, just as we cannot predict that the effect of a pure (nonlabor) income increase will be to increase the demand for children. We are thus left with a useful theoretical framework, but not much else.

As to the empirical estimates, these are based on intercounty differences in the number of children-ever-born to women aged 35-44 and on the expected expenditure on public schooling, the latter presumed to be a proxy for the expected quality of children. As they stand, I find these empirical results far from convincing of the case De Tray intends to make. Concentrating, for example, on the effort to estimate the extent of the complementarity between the wife's nonmarket time and the family's demand for children, one would presumably want to regress completed family size on some permanent wage level. Unfortunately, however, the observed wage rate suffers from the deficiency that it is determined in part by the extent of labor-market experience that a woman has had, and the latter is clearly smaller for women who have larger families. There is thus likely to be a strong negative correlation between completed family size and observed wage rate, but with the causation running from the former to the latter. ${ }^{1}$ This problem would clearly be solved satisfactorily only in a simultaneous-equations framework, but some estimates of the likely biases in De Tray's results might be inferred by using some of the standard methods for analysis of specification error. In practice, however, it is not entirely clear how useful this exercise would be with De Tray's data, since the independent variable in his regressions is not the wage rate of women

\footnotetext{
1 See, e.g., Oaxaca (1971) for estimates from microeconomic data that purport to show this latter relationship and for an explicit discussion of the effect of labor-force experience on the wage rates of women.
} 
but their annual earnings. Now, it is well known that the labor-force participation and weeks worked of women with children are lower than those of women without. Since annual earnings are the product of the wage rate and annual hours, it follows that the number of children a woman has and her annual earnings are likely to have a strong negative correlation, but again with the causation running from the former to the latter. Analyzing the compound effect of these biases is likely to be difficult, particularly when another variable-namely, house value-that is also jointly determined with the demand for children and the demand for the nonmarket time of the wife, is included on the right-hand side of the regression equation.

Though interesting, it will take better data and a more complete model before De Tray's results are likely to convince very many economists that we have reliable estimates of the basic parameters in the application of economic analysis to the determination of family size. 